\title{
cDNA Macroarray Analysis of Gene Expression in Ineffective Nodules Induced on the Lotus japonicus sen1 Mutant
}

\author{
Norio Suganuma, ${ }^{1}$ Atsuko Yamamoto, ${ }^{1}$ Ai Itou, ${ }^{1}$ Tsuneo Hakoyama, ${ }^{1}$ Mari Banba, ${ }^{2}$ Shingo Hata, ${ }^{2}$ \\ Masayoshi Kawaguchi, ${ }^{3}$ and Hiroshi Kouchi ${ }^{4}$ \\ ${ }^{1}$ Department of Life Science, Aichi University of Education, Kariya, Aichi 448-8542, Japan; ${ }^{2}$ Graduate School of Biostudies, \\ Kyoto University, Sakyo-ku, Kyoto 606-8502, Japan; ${ }^{3}$ Department of Biological Sciences, Graduate School of Sciences, \\ University of Tokyo, Hongo, Tokyo 113-0033, Japan; ${ }^{4}$ National Institute of Agrobiological Sciences, Tsukuba, Ibaraki 305- \\ 8602, Japan
}

Submitted 4 March 2004. Accepted 2 July 2004.

\begin{abstract}
The Lotus japonicus sen1 mutant forms ineffective nodules in which development is arrested at the stage of bacterial differentiation into nitrogen-fixing bacteroids. Here, we used cDNA macroarray systems to compare gene expression in ineffective nodules induced on the $\operatorname{sen} 1$ mutant with gene expression in wild-type nodules, in order to identify the host plant genes that are involved in nitrogen fixation. Macroarray analysis coupled with Northern blot analysis revealed that the expression of 18 genes was significantly enhanced in ineffective sen1 nodules, whereas the expression of 30 genes was repressed. Many of the enhanced genes encoded hydrolase enzymes, such as cysteine proteinase and asparaginase, that might function in the early senescence of sen1 nodules. By contrast, the repressed genes encoded nodulins, enzymes that are involved in carbon and nitrogen metabolism, membrane transporters, enzymes involved in phytohormone metabolism and secondary metabolism, and regulatory proteins. These proteins might have a role in the establishment of nitrogen fixation. In addition, we discovered two novel genes that encoded glutamate-rich proteins and were localized in the vascular bundles of the nodules. The expression of these genes was repressed in the ineffective nodules, which had lower levels of nitrogenase activity.
\end{abstract}

Additional keywords: EST, Fix $^{-}$mutant.

The symbiosis between leguminous plants and rhizobia is achieved through the formation of nitrogen-fixing nodules. Many genes in the host plant are involved in this process. Several early nodulin genes have been shown to play a role in nodule organogenesis (Geurts and Bisseling 2002; Schultze and Kondorosi 1998; Stougaard 2000). Their expression is induced by Nod factor or rhizobial infection and leads to the initiation of nodule formation. Many other genes are activated during nodule organogenesis, including those encoding peroxidase, lectins, carbonic anhydrase, chitinases, enzymes of the phenylpropanoid biosynthesis pathway, cyclins, phosphor-

Corresponding author: N. Suganuma; Telephone: +81-566-26-2647; Fax: +81-566-26-2310; E-mail: nsuganum@ auecc.aichi-edu.ac.jp

The nucleotide sequences for glutamate-rich proteins are available in the Genbank, EMBL, and DDBJ databases under accession numbers $\mathrm{AB} 162705$ (LjGluRP1) and AB162706 (LjGluRP2). lipases, and pathogenesis-related proteins. Furthermore, molecular genetic analyses of plant-determined nodulation mutants have recently shown that both the nin gene and plant receptor kinases are essential for nodule formation (Endre et al. 2002; Limpens et al. 2003; Madsen et al. 2003; Radutoiu et al. 2003; Schauser et al. 1999; Stracke et al. 2002).

Nodule development and nitrogen fixation are accompanied by the expression of a range of host plant genes. These include the late nodulin genes, such as those encoding leghemoglobin (Lb) and peribacteroid membrane proteins. Lb supplies oxygen for bacteroid respiration, protects nitrogenase against oxygen damage, and is essential for symbiotic nitrogen fixation (Appleby 1984). Peribacteroid membrane proteins, such as nodulin-26, are thought to be involved in the exchange of nutrients between host plants and endosymbionts (Whitehead and Day 1997). Although the functions of most nodulin genes remain obscure, late nodulin genes are believed to have roles in nodule development and nitrogen fixation because of their specific or highly enhanced expression in nodules. The analysis of nodulin gene expression in ineffective nodules induced on the Pisum sativum E135 mutant has shown that the expression of late nodulin genes encoding cysteine-cluster proteins is closely associated with nitrogenase activity (Kato et al. 2002).

Another group of genes that have a role in nitrogen fixation are those encoding enzymes involved in carbon and nitrogen metabolism, such as sucrose synthase (SS), phosphoenolpyruvate carboxylase (PEPC), glutamine synthetase (GS), and glutamate synthetase. These enzymes function in providing carbon sources for bacteroids and assimilating fixed nitrogen. Nodules induced on the $P$. sativum rug4 mutant, in which SS activity is severely reduced, show decreased nitrogenase activity (Gordon et al. 1999). Furthermore, the expression of these genes is reduced in ineffective nodules with defective nitrogenase activity (Häser et al. 1992; Vance et al. 1994). This highlights the importance of these genes for nitrogen fixation in the nodules.

However, with the exception of the late nodulins and genes encoding enzymes that function in carbon and nitrogen metabolism, little is known about the host genes that are involved in the establishment of nitrogen fixation and in the regulation of rhizobial differentiation and the onset of nitrogenase activity.

Expressed sequence tags (EST) have recently been generated for the model legumes Lotus japonicus and Medicago truncatula, making it possible to analyze global gene expression in their nodules (Colebatch et al. 2002; Fedorova et al. 2002; 
Journet et al. 2002; Mergaert et al. 2003). Furthermore, Kouchi and associates (in press) constructed cDNA macroarrays for $L$. japonicus and analyzed gene-expression profiles during nodule organogenesis and nodule development. We utilized these array systems to compare gene expression in ineffective (Fix ${ }^{-}$) nodules induced on the L. japonicus sen 1 mutant with that in wildtype Gifu nodules. In sen 1 mutants, bacteria are normally endocytosed in the nodule cells but do not differentiate into bacteroids. Furthermore, nitrogenase proteins and nitrogenase activity are not detected, which indicates that nodule development is arrested at the stage of bacterial differentiation into nitrogenfixing bacteroids (Suganuma et al. 2003). We therefore carried out a comparative study of wild type and ineffective sen 1 nodules, in order to identify the host plant genes that are involved in the establishment of nitrogen fixation.

Our study revealed a significant reduction in the expression of several types of gene in sen 1 nodules in addition to those encoding late nodulins and enzymes of the carbon and nitrogen pathway, including genes encoding membrane transporters, enzymes involved in phytohormone metabolism and secondary metabolism, regulatory proteins, and novel glutamate-rich proteins. Our results suggest that these genes have a role in nitrogen fixation.

\section{RESULTS}

\section{Gene-expression analysis using macroarrays.}

After normalizing the differences of signal intensities between filters (discussed below), clones for which normalized signal intensities were above the local background levels were selected. From a total of 18,432 nonredundant clones, 12,745 produced signals that were detected above the local background levels in the wild-type Gifu nodules. The average intensities of the selected clones of the two independent filter arrays for both wild-type Gifu and sen 1 mutant nodules were plotted to compare transcript levels between Gifu and sen 1 nodules (Fig. 1). The majority of data points clustered around the center line, which represents a ratio of 1 , indicating that most of the genes were expressed normally in sen 1 nodules.

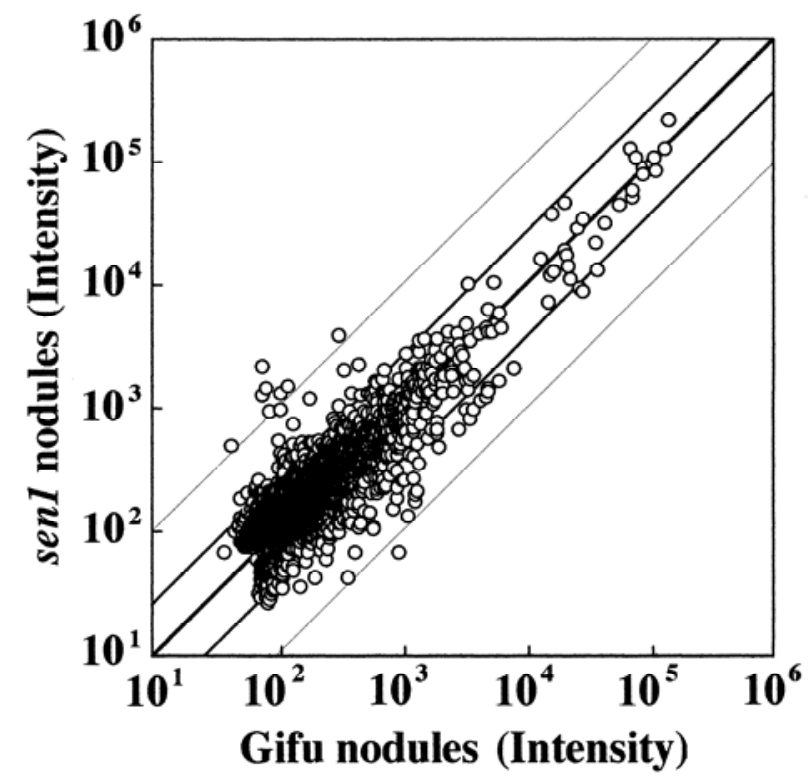

Fig. 1. Scatter plot of the relative transcript levels in wild-type Gifu nodules and Fix $^{-}$mutant sen 1 nodules. The axes represent normalized signal intensities in logarithmic scale and all data points are means of two independent nylon filter arrays. The lines represent ratios of 1 (center), 2.5 , and 10 .
However, clones for which signal intensities in sen 1 nodules were higher or lower than those in the wild-type Gifu nodules were observed. Statistical differences between Gifu nodules and sen 1 mutant nodules relative to the standard deviation of repeated measurements were evaluated by the SAM (Significance Analysis of Microarray) program (Tusher et al. 2001). Furthermore in this study, clones for which signal intensities in sen 1 nodules were less than 0.4 -fold and more than 2.5 -fold than those in Gifu nodules were selected and subjected to further investigation.

\section{Confirmation of expression}

\section{for selected clones using Northern blot analysis.}

A total of 44 clones in the sen 1 mutant nodules had signal intensities that were $>2.5$-fold higher than those in the wildtype Gifu nodules, and 49 clones had signal intensities that were $<0.4$-fold lower. These clones were subjected to Northern blot analysis to confirm the results of the macroarray analysis. Some were found to be homologous genes coding for isoforms such as Lb or cysteine proteinase. In these cases, only one or two of the genes were examined, as they were predicted to cross-hybridize. Northern blot analysis of the first set confirmed that the expression of 18 of the 30 clones examined was enhanced in senl nodules (Fig. 2A); the remaining 12 clones had similar or lower signal intensities compared with those in wild-type Gifu nodules (data not shown). Similarly, Northern blot analysis of the second set showed that the expression of 30 of the 37 clones examined was repressed in sen1 nodules (Fig. 2B); the remaining seven clones displayed similar expression patterns to those in the wild-type Gifu nodules (data not shown).

\section{Gene annotation.}

The nucleotide sequences were determined for the clones with enhanced or repressed expression in sen 1 nodules, and their identities were predicted, using the BLASTX program (Altschul et al. 1997). Tables 1 and 2 list the enhanced and repressed genes, respectively, that were annotated using BLASTX. The genes were categorized by their known or putative functions. One-half of the genes with enhanced expression in the senl nodules encoded hydrolase enzymes such as cysteine proteinase, asparaginase, and phosphatase. In addition, metallothionein and ferritin genes were also present in this group. By contrast, the genes that were repressed in the sen 1 nodules included those encoding nodulins, such as Nlj21 and $\mathrm{Lb}$, and enzymes involved in carbon and nitrogen metabolism, such as SS, PEPC, and asparagines synthetase (AS). Moreover, genes encoding membrane transporters, enzymes involved in phytohormone metabolism and secondary metabolism, and regulatory proteins were also found among this group. Two clones showed similarities to a hypothetical protein of Cicer arietinum and homologs of four clones were found in Arabidopsis thaliana. However, the remaining two clones were not identified.

\section{Genes encoding glutamate-rich proteins.}

As the genes that were repressed in the senl nodules were predicted to be involved in the establishment of nitrogen fixation, we further investigated the two clones that were homologous to a hypothetical protein of $C$. arietinum (Table 2). Although the similarities between the predicted amino acid sequences of these two clones and of the $C$. arietinum gene were relatively low, both predicted proteins appeared to be characterized by high glutamate levels. MWM066c03 and MWM187g02, designated LjGluRP1 and LjGluRP2, respectively, encoded relatively small acidic proteins with a high glutamate content (Fig. 3; Table 3). Their predicted amino acid 


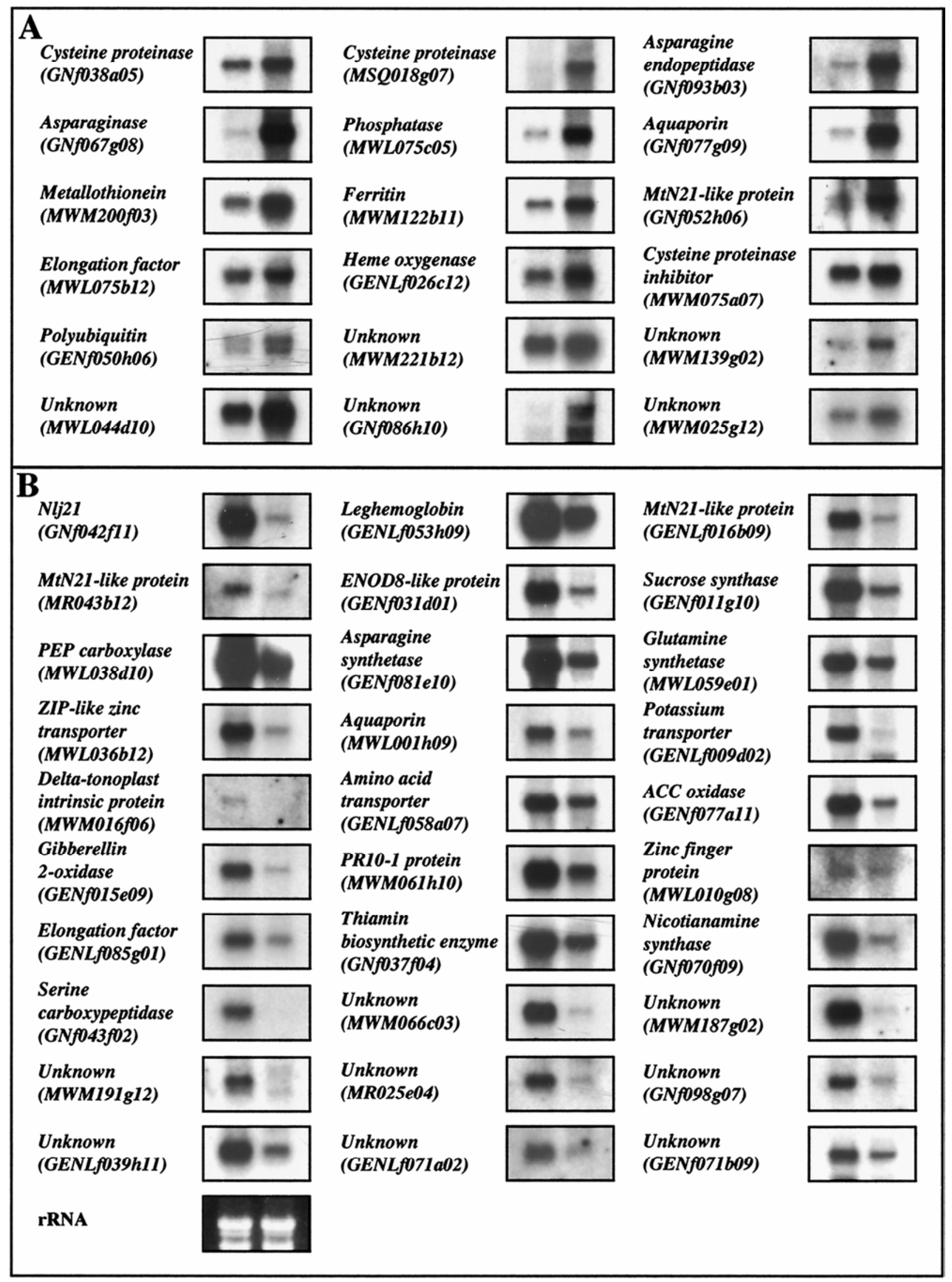

Fig. 2. Northern blot analysis of mRNA for the genes that were A, enhanced and $\mathbf{B}$, repressed in the sen 1 mutant nodules, according to the array analysis. The left column represents the wild-type Gifu nodules and the right column represents the sen 1 nodules. Each sample of total RNA (5 $\mu$ g) was subjected to electrophoresis on a $1.25 \%(\mathrm{wt} / \mathrm{vol})$ agarose gel that contained formaldehyde and then was transferred to a nylon membrane and hybridized with radiolabeled probes. rRNA was stained with ethidium bromide. 
sequences were not highly similar each other, and they lacked characteristic motifs that were common to both, except in the $\mathrm{N}$-terminal region. However, no cleavable signal peptide sequences deposited in the database matched their N-terminal sequences. Southern blot analysis detected one and two bands, respectively, for these genes (Fig. 4). Genes encoding glutamate-rich proteins were found not only in legumes but also in several other plant species (Table 3).

The level of expression of LjGluRPl in the effective nodules was remarkably high, and it was also detected in the roots, cotyledons, stems, flowers, and pods (Fig. 5). Similarly, the expression of LjGluRP2 was particularly high in the nodules, and it was also significantly expressed in the flowers. The expression of these genes was induced by inoculation with Mesorhizobium loti and increased in the nodules in a way similar to that of Lb (Fig. 5). Within the nodule tissue however, the transcripts were detected exclusively in the vascular bundles, as opposed to those of $\mathrm{Lb}$, which were detected in infected cells (Fig. 6). The expression of LjGluRPl and LjGluRP2 was repressed in ineffective nodules induced on sen 1, fen 1, and Ljsym81 mutants and in early senescent nodules induced on Gifu plants inoculated with Rhizobium etli, which showed lower levels of nitrogenase activities (Fig. 7).

\section{DISCUSSION}

cDNA macroarrays combined with Northern blot analysis revealed 18 genes with enhanced expression and 30 genes with reduced expression in the ineffective nodules induced on sen 1 mutants of $L$. japonicus. This corresponded to $<1 \%$ of the total number of genes expressed in the nodules. These results suggest that the majority of genes were expressed in the nodules irrespective of the presence or absence of nitrogenase activity. However, in this study, we limited the genes examined by selecting only those that were expressed in sen 1 mutant nodules at levels $<0.4$-fold lower or $>2.5$-fold higher than in wild-type Gifu nodules. This may lead to the results showing that the expression of so few genes is influenced by the Senl mutation in ineffective nodules. Kouchi and associates (in press) reported that the level of expression of a total 1,353 genes fluctuated during nodule organogenesis and development. In addition, M. Banba and S. Hata (unpublished data) analyzed gene expression in ineffective nodules induced on Gifu plants inoculated with $R$. etli using cDNA macroarray filters. They found a total of approximately 1,000 genes with altered expression levels in ineffective nodules in comparison with effective nodules. Although characteristics of senl mutant nodules are not the same as ineffective nodules induced by $R$. etli, it may be possible that greater numbers of genes than suggested by the present results are differentially expressed in sen 1 nodules. The numbers of genes of which expression was potentially enhanced or repressed in senl nodules increased when the criteria were loosened to levels $<0.5$-fold lower or $>2.0$-fold higher than in wild-type Gifu nodules. Expression analyses of these genes in sen 1 nodules are now under investigation. The genes included in our analysis are likely, therefore, to represent only those whose expression was significantly influenced by ineffectiveness induced by Sen 1 mutation.

Genes encoding hydrolase enzymes, such as cysteine proteinase, asparaginase, and phosphatase, showed highly enhanced levels of expression in senl mutant nodules (Fig. 2; Table 1). We propose that this is the result of early senescence. Pladys and Vance (1993) showed that cysteine proteinase activity increases during premature senescence in ineffective alfalfa nodules. In addition, genes encoding ferritin, metallothionein, polyubiquitin, and heme oxygenase, all of which are closely associated with senescence, were enhanced in sen 1 nodules. Ferritin proteins have been reported to accumulate in dark-induced senescing lupin nodules (Hernández-Jiménez et al. 2002), and the expression of metallothionein is known to

Table 1. Genes whose expression was enhanced in the sen 1 mutant nodules as compared with wild-type Gifu nodules ${ }^{\mathrm{a}}$

\begin{tabular}{|c|c|c|c|c|c|}
\hline Category & Gene ID & Annotation or Best homology (BLASTX E Value) & Gifu $^{b}$ & $\operatorname{sen} 1^{b}$ & sen1/Gifu \\
\hline \multirow[t]{12}{*}{ Proteolysis } & GNf032f12 & Cysteine proteinase, Medicago truncatula AY336982 (4e-79) & 75 & 2,232 & 29.7 \\
\hline & GNf089d01 & Cysteine proteinase, Astragalus sinicus AB040454 (3e-79) & 81 & 1,501 & 18.5 \\
\hline & GNf037h07 & Cysteine proteinase, Astragalus sinicus AB040454 (5e-52) & 77 & 1,280 & 16.5 \\
\hline & GNf071h01 & Cysteine proteinase, Ipomoea batatas AY055589 (2e-44) & 87 & 956 & 11.0 \\
\hline & MR033e07 & Cysteine proteinase, Cicer arietinum T09528 (5e-68) & 314 & 1,053 & 3.3 \\
\hline & GNf078d09 & Cysteine proteinase, Phaseolus vulgaris T12039 (3e-65) & 132 & 412 & 3.1 \\
\hline & GNf038a05 & Cysteine proteinase, Pisum sativum S71923 (3e-90) & 482 & 1,277 & 2.7 \\
\hline & MWL004h04 & Cysteine proteinase, Pisum sativum AJ251535 (9e-68) & 65 & 174 & 2.7 \\
\hline & GENf013h02 & Cysteine proteinase, Phaseolus vulgaris T12040 (6e-73) & 1,403 & 3,593 & 2.6 \\
\hline & GNf100c03 & Cysteine proteinase, Phaseolus vulgaris T12041 (2e-91) & 1,095 & 2,827 & 2.6 \\
\hline & MSQ002b05 & Cysteine proteinase, Glycine max AB092555 (2e-58) & 135 & 431 & 3.2 \\
\hline & GNf093b03 & Asparagine endopeptidase, Phaseolus vulgaris T12043 (4e-87) & 182 & 1,206 & 6.6 \\
\hline \multirow[t]{3}{*}{ Hydrolysis } & MWM005g11 & L-Asparaginase, Glycine max AY096000 (2e-73) & 43 & 501 & 11.6 \\
\hline & GNf017h08 & L-Asparaginase, Oryza sativa AL442007 (6e-11) & 107 & 994 & 9.3 \\
\hline & MWL075c05 & Phosphatase, Phaseolus vulgaris AJ518838 (1e-67) & 76 & 208 & 2.7 \\
\hline Transporter & GNf021a08 & Aquaporin, Lotus japonicus AF275316 (3e-73) & 133 & 763 & 5.7 \\
\hline \multirow[t]{3}{*}{ Metal binding } & MWM200f03 & Metallothionein, Fagus sylvatica AJ130886 (1e-26) & 353 & 2,098 & 6.0 \\
\hline & MSQL089f11 & Metallothionein, Glycine max JQ2128 (8e-39) & 195 & 535 & 2.7 \\
\hline & MWM122b11 & Ferritin, Glycine max AY049920 (1e-48) & 136 & 415 & 3.1 \\
\hline Nodulin & GNf052h06 & MtN21-like protein, Medicago truncatula O24091 (e-138) & 113 & 330 & 2.9 \\
\hline Regulation & MWM139g02 & NAM-like protein, Arabidopsis thaliana AL391711 (9e-55) & 88 & 243 & 2.8 \\
\hline Protein synthesis & MWL075b12 & Elongation factor EF-1 alpha, Arabidopsis thaliana X16432 (5e-83) & 66 & 216 & 3.3 \\
\hline Secondary metabolism & GENLf026c12 & Heme oxygenase, Pisum sativum AF276228 (3e-20) & 650 & 1,644 & 2.5 \\
\hline Inhibitor & MWM075a07 & Cysteine proteinase inhibitor, Citrus paradisi AF283536 (3e-23) & 115 & 298 & 2.6 \\
\hline \multirow[t]{2}{*}{ Ubiquitin } & GENf050h06 & Polyubiquitin, Arabidopsis thaliana H85066 (2e-93) & 745 & 2,062 & 2.8 \\
\hline & MWM224h10 & Polyubiquitin, Elaeagnus umbellata O65332 (2e-70) & 219 & 550 & 2.5 \\
\hline \multirow[t]{4}{*}{ Unknown } & MWM221b12 & Auxin-repressed protein, Robinia pseudoacacia AY009094 (6e-36) & 402 & 1,337 & 3.3 \\
\hline & MWL044d10 & Hypothetical protein, Arabidopsis thaliana T10667 (3e-52) & 84 & 239 & 2.8 \\
\hline & GNf086h10 & No homology & 136 & 511 & 3.8 \\
\hline & MWM025g12 & No homology & 114 & 366 & 3.2 \\
\hline
\end{tabular}

\footnotetext{
${ }^{a}$ As determined by cDNA array analysis coupled with Northern blot analysis.

${ }^{\mathrm{b}}$ Means of normalized signal intensities from two independent nylon filter arrays.
} 
respond to a range of stresses, including carbon and nitrogen starvation (Lanfranco et al. 2002). Park and associates (1998) showed that the expression of genes encoding polyubiquitin is induced during leaf senescence in several plant species. Finally, heme oxygenase is known to function in the breakdown of heme. Therefore, the enhanced expression of specific genes in the sen 1 mutant nodules, including those with unknown functions such as auxin-repressed or no apical meristem-like proteins, might be induced by premature senescence. In fact, several morphological features indicating bacterial degradation have been observed in sen 1 nodules at relatively early stages (Suganuma et al. 2003). In the present study, we used senl nodules from 24-day-old plants, in order not only to exclude senescent nodules but also to ensure sufficient material was available for our analyses. However, our results suggest that senescence had already begun in the sen 1 nodules of the 24day-old plants. This therefore suggests that an absence of nitrogenase activity might induce premature senescence, even when the nodules are formed and their cells are endocytosed by rhizobia.

The genes that encode cysteine proteinase comprise a multigene family in the legume Astragalus sinicus (Naito et al. 2000). In the present study, 11 clones were predicted to encode cysteine proteinase (Table 1), indicating that the $L$. japonicus genome might also contain multiple cysteine proteinase genes. The array analysis revealed variability in the expression of these genes and in the ratios of their expression in Gifu and senl nodules (Table 1). This suggests that their expression is differentially regulated during nodule development. The increased expression of cysteine proteinase genes in the sen 1 nodules was accompanied by increased expression of cysteine proteinase inhibitor genes (Fig. 2; Table 1). Manen and associates (1991) reported that a nodulin gene encoding Kunitz protease inhibitor was expressed during the senescence of nodules of the winged bean (Psophocarpus tetragonolobus). Therefore, the enhanced expression of cysteine proteinase inhibitor genes might also be associated with premature senescence in the sen 1 nodules.

The reasons for the increased expression of an aquaporin (Lotus intrinsic membrane protein 2), MtN21-like proteins, and elongation factor in ineffective senl nodules remain unknown. Enhanced expression of these genes might be the result of a deficiency in feedback regulation owing to the lack of nitrogenase activity. Lotus intrinsic membrane protein 2 is a nodulin and a multifunctional aquaglyceroporin and is thought to have an important role in nitrogen-fixing symbiosis (Guenther and Roberts 2000). The expression of a second aquaporin, Lotus intrinsic membrane protein 1, was found to be repressed in sen1 nodules (Fig. 2; Table 2). This suggests that these membrane proteins have distinct and diverse functions.

By contrast, the 30 genes with reduced expression levels in senl nodules appeared to be associated with the establishment of nitrogen fixation. This group included genes encoding nodulins, such as Lb, and enzymes that are involved in carbon and nitrogen metabolism. Reduced $\mathrm{Lb}$ expression has also been reported in the ineffective nodules of alfalfa, pea, cow-

Table 2. Genes of which expression was repressed in the sen1 mutant nodules compared to the wild-type Gifu nodules ${ }^{\mathrm{a}}$

\begin{tabular}{|c|c|c|c|c|c|}
\hline Category & Gene ID & Annotation or Best homology (BLASTX E Value) & Gifu $^{b}$ & $\operatorname{sen} 1^{\mathbf{b}}$ & Gifu/sen1 \\
\hline \multirow[t]{7}{*}{ Nodulin } & GNf042f11 & Nlj21, Lotus japonicus AF000402 (e-101) & 1,324 & 199 & 6.6 \\
\hline & GENLf039f11 & Leghemoglobin, Lotus japonicus AB042718 (1e-76) & 8,067 & 2,116 & 3.8 \\
\hline & GENLf053h09 & Leghemoglobin, Lotus japonicus AB042717 (1e-53) & 29,456 & 8,812 & 3.3 \\
\hline & GENLf016c06 & Leghemoglobin, Lotus japonicus AB042716 (5e-62) & 39,231 & 13,579 & 2.9 \\
\hline & GENLf016b09 & MtN21-like protein, Medicago truncatula O24091 (5e-24) & 751 & 239 & 3.1 \\
\hline & MR043b12 & MtN21-like protein, Medicago truncatula O24091 (6e-64) & 459 & 168 & 2.7 \\
\hline & GENf031d01 & ENOD8-like protein, Medicago sativa S59943 (1e-76) & 393 & 139 & 2.8 \\
\hline \multirow[t]{5}{*}{ Carbon metabolism } & MSQL073a06 & Sucrose synthase, Glycine max $\mathrm{P} 13708$ (e-141) & 2,014 & 485 & 4.2 \\
\hline & GNf029d01 & Sucrose synthase, Vigna radiata Q01390 (e-120) & 1,023 & 260 & 3.9 \\
\hline & MWM120b01 & Sucrose synthase, Pisum sativum $081610(3 \mathrm{e}-48)$ & 1,280 & 404 & 3.2 \\
\hline & GENf011g10 & Sucrose synthase, Glycine $\max \mathrm{P} 13708$ (3e-82) & 1,993 & 679 & 2.9 \\
\hline & MWM032e12 & PEP carboxylase, Lotus japonicus AB092820 (2e-41) & 589 & 208 & 2.8 \\
\hline \multirow[t]{4}{*}{ Nitrogen metabolism } & GENf034g08 & Asparagine synthetase, Lotus japonicus S69183 (2e-76) & 4,968 & 1,262 & 3.9 \\
\hline & GNf021f11 & Asparagine synthetase, Lotus japonicus S69183 (3e-81) & 1,386 & 363 & 3.8 \\
\hline & MWM225f07 & Asparagine synthetase, Lotus japonicus S69182 (3e-63) & 640 & 208 & 3.1 \\
\hline & MWL059e01 & Glutamine synthetase, Lotus japonicus X94299 (1e-90) & 734 & 264 & 2.8 \\
\hline \multirow[t]{5}{*}{ Transporter } & MWL036b12 & ZIP-like zinc transporter, Thlaspi caerulescens AF275752 (e-153) & 252 & 59 & 4.3 \\
\hline & MWL001h09 & Aquaporin, Lotus japonicus AF275315 (e-138) & 453 & 110 & 4.1 \\
\hline & GENLf009d02 & Potassium transporter, Oryza sativa AJ427975 (e-127) & 388 & 124 & 3.1 \\
\hline & MWM016f06 & Delta-tonoplast intrinsic protein, Gossypium hirsutum T10804 (e-117) & 111 & 36 & 3.1 \\
\hline & GENLf058a07 & Amino acid transporter, Arabidopsis thaliana AB009048 (1e-31) & 810 & 293 & 2.8 \\
\hline \multirow[t]{3}{*}{ Phytohormone metabolism } & GENf077a11 & ACC oxidase, Pisum sativum $\mathrm{P} 31239$ (e-160) & 877 & 154 & 5.7 \\
\hline & GNf071h07 & ACC oxidase, Pisum sativum $\mathrm{P} 31239$ (2e-12) & 918 & 187 & 4.9 \\
\hline & GNf087h07 & Gibberellin 2-oxidase, Lactuca sativa AB031206 (2e-33) & 1,055 & 263 & 4.0 \\
\hline Pathogenesis & MWM061h10 & PR10-1 protein, Medicago truncatula P93333 (6e-63) & 404 & 117 & 3.5 \\
\hline Regulation & MWL010g08 & Zinc finger protein, Solanum tuberosum AJ242853 (7e-27) & 354 & 126 & 2.8 \\
\hline Protein synthesis & GENLf085g01 & Elongation factor-1 alpha, Nicotiana paniculata AB019427 (e-120) & 857 & 328 & 2.6 \\
\hline \multirow[t]{2}{*}{ Secondary metabolism } & GNf037f04 & Thiamin biosynthetic enzyme, Citrus sinensis T10474 (6e-61) & 1,965 & 641 & 3.1 \\
\hline & GNf070f09 & Nicotianamine synthase, Lycopersicon esculentum AJ242045 (e-100) & 262 & 96 & 2.7 \\
\hline Proteolysis & GNf043f02 & Serine carboxypeptidase, Arabidopsis thaliana G86244 (e-150) & 317 & 100 & 3.2 \\
\hline \multirow[t]{8}{*}{ Unknown } & MWM066c03 & Hypothetical protein, Cicer arietinum AJ225026 (2e-31) & 965 & 68 & 14.3 \\
\hline & MWM187g02 & Hypothetical protein, Cicer arietinum AJ225026 (6e-21) & 373 & 42 & 8.9 \\
\hline & MWM191g12 & Hypothetical protein, Arabidopsis thaliana AY086126 (4e-74) & 154 & 36 & 4.3 \\
\hline & $\mathrm{MR} 025 \mathrm{e} 04$ & Hypothetical protein, Arabidopsis thaliana AL132960 (2e-34) & 943 & 233 & 4.1 \\
\hline & GNf098g07 & Hypothetical protein, Arabidopsis thaliana AY136388 (e-141) & 478 & 116 & 4.1 \\
\hline & GENLf039h11 & No homology & 4,448 & 1,154 & 3.9 \\
\hline & GENLf071a02 & No homology & 317 & 116 & 2.7 \\
\hline & GENf071b09 & Hypothetical protein, Arabidopsis thaliana AE005173 (5e-88) & 1,950 & 779 & 2.5 \\
\hline
\end{tabular}

\footnotetext{
${ }^{a}$ As determined by cDNA array analysis coupled with Northern blot analysis.

${ }^{\mathrm{b}}$ Means of normalized signal intensities from two independent nylon filter arrays.
} 
pea, and Vicia faba mutants to varying degrees, depending on the mutant (Häser et al. 1992; Kawashima et al. 2001; Purdom and Tress 1995; Vance et al. 1994). In addition, reduced expression levels of genes encoding SS and PEPC, which are involved in carbon metabolism, and AS and GS, which are involved in nitrogen metabolism, have been reported in the ineffective nodules of alfalfa and pea (Pathirana et al. 1992; Robinson et al. 1999; Shi et al. 1997, 1999; Suganuma et al. 1997; Vance et al. 1994). SS breaks down sucrose that is translocated to the nodules from the shoots, PEPC produces malate by recovering carbon dioxide and supports nitrogen fixation in bacteroids, and AS and GS assimilate ammonia during nitrogen fixation. The consistency of these results suggests that our macroarray analysis accurately detected differences in gene expression between the senl mutant and wildtype Gifu nodules.

Among the nodulins, the gene encoding Nlj21 showed the greatest reduction in expression levels in the sen1 nodules (Fig. 2; Table 2). Nlj21 is characterized by a high glutamate content, although its function remains unknown (Szczyglowski et al. 1997). The present study also revealed two genes, LjGluRP1 and LjGluRP2, which had notably reduced expression levels in the senl nodules and were predicted to encode novel glutamate-rich proteins (Fig. 3). The lengths of their predicted amino acids were shorter than those of $\mathrm{Nlj} 21$, and they were not nodulins (Table 3; Fig. 5). The expression levels of both genes were high in the effective nodules, although they were also expressed in other tissues. The coding region of LjGluRPl contained a restriction site for BamHI but not HindIII, whereas LjGluRP2 did not contain either site. Southern blot analysis indicated that a single gene in the Lotus genome encoded the LjGluRP1 protein, and on the basis of these results, we predicted that this was also the case for LjGluRP2 (Fig. 4). These results suggest that each gene has a role not only in nitrogen fixation but also in plant development. Furthermore, their predicted amino acid sequences have highly similar N-terminal regions, although the cleavable signal peptide has not yet been identified. Therefore, it seems likely that they act in a similar way in each tissue.

The expression of glutamate-rich proteins has also been reported in actinorhizal nodules (Guan et al. 1997), kiwi fruit (Ledger and Gardner 1994), and grape berries (Davies and Robinson 2000) (Table 3). In actinorhizal nodules, ag13, encoding glutamate-rich proteins, was expressed in the pericycle of the nodule vascular bundles and in infected cells showing degradation of the endosymbiont. In the present study, the expression of both LjGluRPI and LjGluRP2 was detected in the vascular bundles of the nodules but not in infected cells (Fig. 6). In addition, the expression of these genes was also repressed in ineffective nodules with lower levels of nitrogenase activity (Fig. 7). These results suggest that LjGluRP1 and LjGluRP2 are associated with the development of nodule structure rather than nitrogenase activity. The structure of sen 1 nodules resembles that of wild-type nodules, and vascular bundles are observed in both (Suganuma et al. 2003). However, neither LjGluRP1 nor LjGluRP2 was expressed in the vascular bundles of the sen 1 nodules (data not shown). Therefore, we suggest that LjGluRP1 and LjGluRP2 are not required for the formation of vascular bundles in the nodules. Glutamate-rich proteins, however, might function as cell wall proteins, as suggested by Guan and associates (1997).

Among the nodulins that were repressed in the senl nodules, we identified homologs of the ENOD 8 and MtN21 genes. The expression of ENOD 8 has been detected in empty alfalfa nodules induced by exopolysaccharide-deficient Rhizobium meliloti, and it is thought to be associated with nodule structure (Dickstein et al. 1993). The reduced expression of ENOD 8 might be the result of suspended nodule development in the senl mutant, in which the nodules remain small (Suganuma et al. 2003). MtN21 has been isolated among other proteins that are excessively expressed during nodulation in Medicago truncatula by subtractive hybridization with the roots, although its

\begin{tabular}{|c|c|c|}
\hline LjGIURP1 & MASVEVAQQAPTTVVQENEPT-EVTKIQETIPEPEQPAATEVAAPEQPAAEVPAPAE & 56 \\
\hline LjGluRP2 & MASVEVAQQVPTPVEQI-ETFQE-TTI---_--EQPAS-EVPAPE-PTIEQEHPKE & 46 \\
\hline & $* * * * \quad * * * * * * \quad * \quad * *$ & \\
\hline LjGIURP1 & PATEEPKEETTEEPKETETETEAPVAPETQDPLEVENKEVTEEAKPEEVKPET-E-K & 113 \\
\hline LjGIURP2 & ETTEEPKVEAVAETTT-E---APAAPETEAPAEVETKEVTEETKPEAEKTEEPEVK & 100 \\
\hline & $* * * * * * \quad * * * * * * * * * * * * * * \quad * * \quad * *$ & \\
\hline LjGIURP1 & TEE-KTEEPKTEEPAATTETESAAPVEEENKPAEEAPV-EV-VP-_-_-VEKTEA & 158 \\
\hline LjGIuRP2 & PEEVK-EEPIVEETKETAATE-AAPVEEE-KSSEESKAAETTVEATTEVAIEKTEA & 151 \\
\hline
\end{tabular}

Fig. 3. The predicted amino-acid sequences of LjGluRP1 (MWM066c03) and LjGluRP2 (MWM187g02). The asterisks represent identical amino acid residues in both sequences.

Table 3. Comparison of characteristics of glutamate-rich proteins isolated from legumes and other plant species

\begin{tabular}{|c|c|c|c|c|c|c|}
\hline \multirow[b]{2}{*}{ Gene } & \multirow{2}{*}{$\begin{array}{l}\text { Length of polypeptide } \\
\text { (aa) }\end{array}$} & \multirow{2}{*}{$\begin{array}{l}\text { Molecular mass } \\
\text { (kDa) }\end{array}$} & \multirow[b]{2}{*}{ Calculated pI } & \multirow[b]{2}{*}{ Glu composition } & \multicolumn{2}{|c|}{ Homology\% } \\
\hline & & & & & LjGluRPI & LjGluRP2 \\
\hline LjGluRP1 & 158 & 17.1 & 3.76 & 29.8 & l & I \\
\hline LjGluRP2 & 151 & 16.4 & 3.85 & 30.5 & 53.8 & 1 \\
\hline Nlj21 (Lotus japonicus) & 192 & 21.0 & 4.00 & 27.1 & 33.3 & 32.0 \\
\hline Hypothetical protein (Cicer arietinum) & 168 & 18.0 & 3.58 & 28.6 & 57.2 & 47.7 \\
\hline Ag13 (Alnus glutinosa) & 185 & 19.8 & 4.03 & 28.1 & 37.8 & 40.2 \\
\hline Fruit protein (Actinidia chinensis) & 184 & 18.9 & 3.57 & 26.1 & 37.6 & 37.6 \\
\hline Grip 31 (Vitis vinifera) & 173 & 18.4 & 3.76 & 29.5 & 37.3 & 41.4 \\
\hline Grip 68 (Vitis vinifera) & 152 & 15.9 & 3.79 & 33.6 & 44.5 & 44.3 \\
\hline Latex allergen (Hevea brasiliensis) & 151 & 16.1 & 3.90 & 30.5 & 43.8 & 48.4 \\
\hline
\end{tabular}


function remains unknown (Gamas et al. 1996). MR043b12 had high similarity to $M t N 21$, whereas the similarity between GENLf016b09 and MtN21 was relatively low. An additional gene with an MtN21-like protein product was identified among the genes with enhanced expression in the sen 1 nodules. Many genes encoding MtN21-like proteins have been described in the A. thaliana genome. Therefore, on the basis of these results, we suggest that the genes encoding MtN21-like proteins constitute a multigene family and are involved not only in nodule development but also in plant development.

The expression of genes encoding several membrane transporters was reduced in the sen 1 nodules (Fig. 2; Table 2). Sulfate transporters were identified as nodulins in L. japonicus

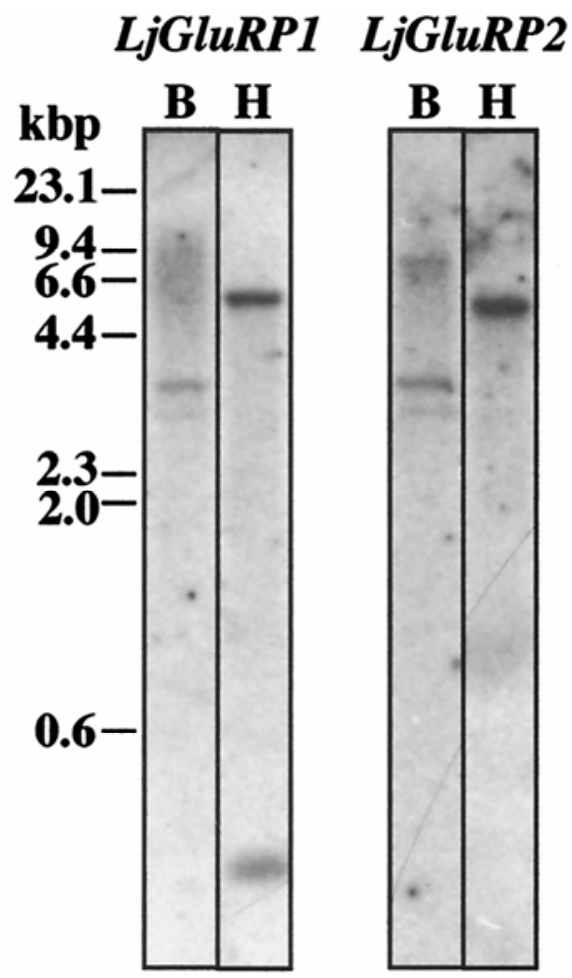

Fig. 4. Southern blot analyses of $L j G l u R P 1$ and $L j G l u R P 2$. Genomic DNA was isolated from the leaves of 3-month-old Gifu plants. Genomic DNA $(10 \mu \mathrm{g})$ was restricted with BamHI (B) and HindIII (H) and then was fractionated on a $0.8 \%(\mathrm{wt} / \mathrm{vol})$ agarose gel, transferred to a nylon membrane, and hybridized with radiolabeled probes.
EST isolated by Colebatch and associates (2002). Although the EST in our macroarray analysis revealed several clones encoding sulfate transporter, the expression of these genes in the sen 1 mutant nodules did not significantly differ from that in the Gifu nodules (data not shown). Zinc transporter (Moreau et al. 2002), potassium transporter (Colebatch et al. 2002), and an aquaporin (Lotus intrinsic membrane protein 1) (Guenther and Roberts 2000) are all expressed specifically in nodules on soybean and L. japonicus. Furthermore, zinc transporter is localized to the peribacteroid membrane. These results indicate that the transporters are localized to the peribacteroid membrane and play a role in transporting materials from the host plants to the endosymbionts. The levels of expression of zinc transporter, potassium transporter, and an aquaporin were significantly reduced in senl nodules, indicating that their expression is more closely correlated with nitrogenase activity than that of other transporters. In the early stages of the development of sen 1 nodules, bacteria are normally enclosed in a peribacteroid membrane (Suganuma et al. 2003). However, this membrane might not be fully functional in the sen1 mutant nodules.

The reduced expression of 1-aminocyclopropane-1- carboxylate (ACC) oxidase and gibberellin 2 oxidase, which are involved in ethylene and gibberellin metabolism, respectively, indicated that these plant hormones might be involved in the establishment of nitrogen fixation, although their precise roles in the process are unknown. It has previously been reported that soybean nodules produce ethylene (Hunter 1993), and ACC oxidase catalyzes the conversion of ACC to ethylene. Therefore, the repression of the expression of ACC oxidase in ineffective nodules suggests that ethylene production has a role in effective nodules. Gibberellins are also present at greater concentrations in nodules than in roots (Dobert et al. 1992). However, gibberellin 2 oxidase catabolizes gibberellins. Therefore, the repression of the expression of gibberellin 2 oxidase in ineffective nodules implies that gibberellin might have a negative influence on the effectiveness of nodules. Colebatch and associates (2002) showed enhanced expression of both gibberellin 2 oxidase and Ent-kaurene synthase A, which is a gibberellin biosynthetic enzyme, in $L$. japonicus nodules. Further studies will be required to clarify the hormonal regulation of nitrogen fixation and nodule development.

Genes encoding a zinc-finger protein and elongation factor that are involved in gene expression and translation were detected among those repressed in the sen 1 nodules. Colebatch

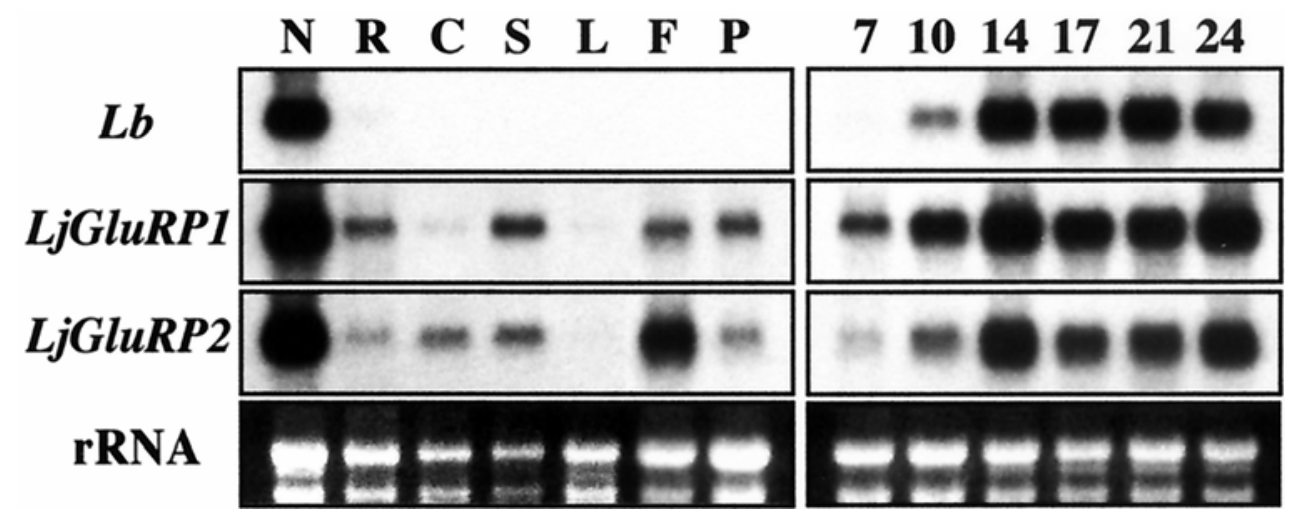

Fig. 5. Northern blot analysis of LjGluRP1 and LjGluRP2 mRNA. Total RNA was isolated from the tissues (left) and from the roots and nodules (right) of Gifu plants at the following stages of development: nodules (N), roots (R), and cotyledons (C) were harvested from 3-week-old plants; stems (S), leaves (L), flowers (F), and pods (P) were obtained from 3-month-old plants; and 7-day-old uninoculated roots (7), 10-day-old inoculated roots (10) and effective nodules $(14,17,21$, and 24 days) were harvested after sowing. Leghemoglobin $(L b)$ was used as a reference. Each sample of total RNA (5 $\mu$ g) was subjected to electrophoresis on a $1.25 \%$ (wt/vol) agarose gel that contained formaldehyde, was transferred to a nylon membrane, and was hybridized with radiolabeled probes. rRNA was stained with ethidium bromide. 
and associates (2002) identified a nodule-specific zinc-finger protein in L. japonicus nodules. In addition, Frugier and associates (2000) reported that Krüppel-like zinc-finger protein was involved in nodule organogenesis. The zinc-finger protein and elongation factor identified in our study are likely to have specific roles in the establishment of nitrogen fixation. The expression of PR10-1, thiamine biosynthetic enzyme, nicotianamine synthase, and serine carboxypeptidase was also repressed in sen1 nodules (Fig. 2; Table 2), which suggests that they are required for nitrogen fixation. Expression of the pathogenesis-related protein PR10-1 has been reported in nodules on Medicago truncatula (Gamas et al. 1998) at lower levels in the nodules than in the roots. Furthermore, in nodules of the yellow lupine (Lupinus luteus), PR10 is constitutively expressed in the roots, and its expression is reduced in young and mature nodules, although not in senescent nodules (Sikorski et al. 1999). By contrast, we found the expression of PR10-1 to be lower in senescent sen 1 nodules than in mature Gifu nodules. These results indicate that the expression of PR10-1 might be associated with nodule development rather than senescence, although the precise function of the PR10-1 protein is unknown. In addition, the roles of thiamine biosynthetic enzyme, nicotianamine synthase, and serine carboxypeptidase in nitrogen fixation are also unclear. Moreover, several unknown genes that were repressed in the senl nodules might be important for the establishment of nitrogen fixation; the expression levels of MWM191g12, MR025e04, GNf098g07, and GENLf071a02 were all notably repressed in sen 1 nodules.
The characterization of these genes will provide new insight into the regulation of symbiotic nitrogen fixation by host plants.

In conclusion, the present study revealed 30 genes that are predicted to be involved in the establishment of nitrogen fixation. Gene expression in ineffective nodules on wild-type Gifu plants inoculated with $R$. etli was analyzed by M. Banba and S. Hata (unpublished data), using cDNA macroarray filters. All the nodulin genes and the genes with unknown identities (except GENf071b09 in the 30 repressed genes) (Table 2) were similarly detected as repressed genes in their results. However, the genes involved in carbon and nitrogen metabolism detected in our study and some other genes, for instance, those encoding amino acid transporter, ACC oxidase, zinc finger protein, and nicotianamine synthase, were found to be specifically repressed in sen l mutant nodules only. These differences might reflect the stage at which development was arrested in the ineffective nodules in the two studies. In the sen 1 mutant nodules, the bacteria did not differentiate into bacteroids, and the expression of nitrogenase was blocked; by contrast, in the $R$. etli-induced nodules, the bacteria differentiated and nitrogenase was expressed. In addition to the senl mutant used in the present study, fenl and Ljsym81 mutants that are arrested at the nodule developmental stage are also available. Comparative studies of gene expression among these additional ineffective nodules and further analysis of genetically manipulated plants will allow us to clarify the functions of host genes in the establishment of nitrogen fixation.

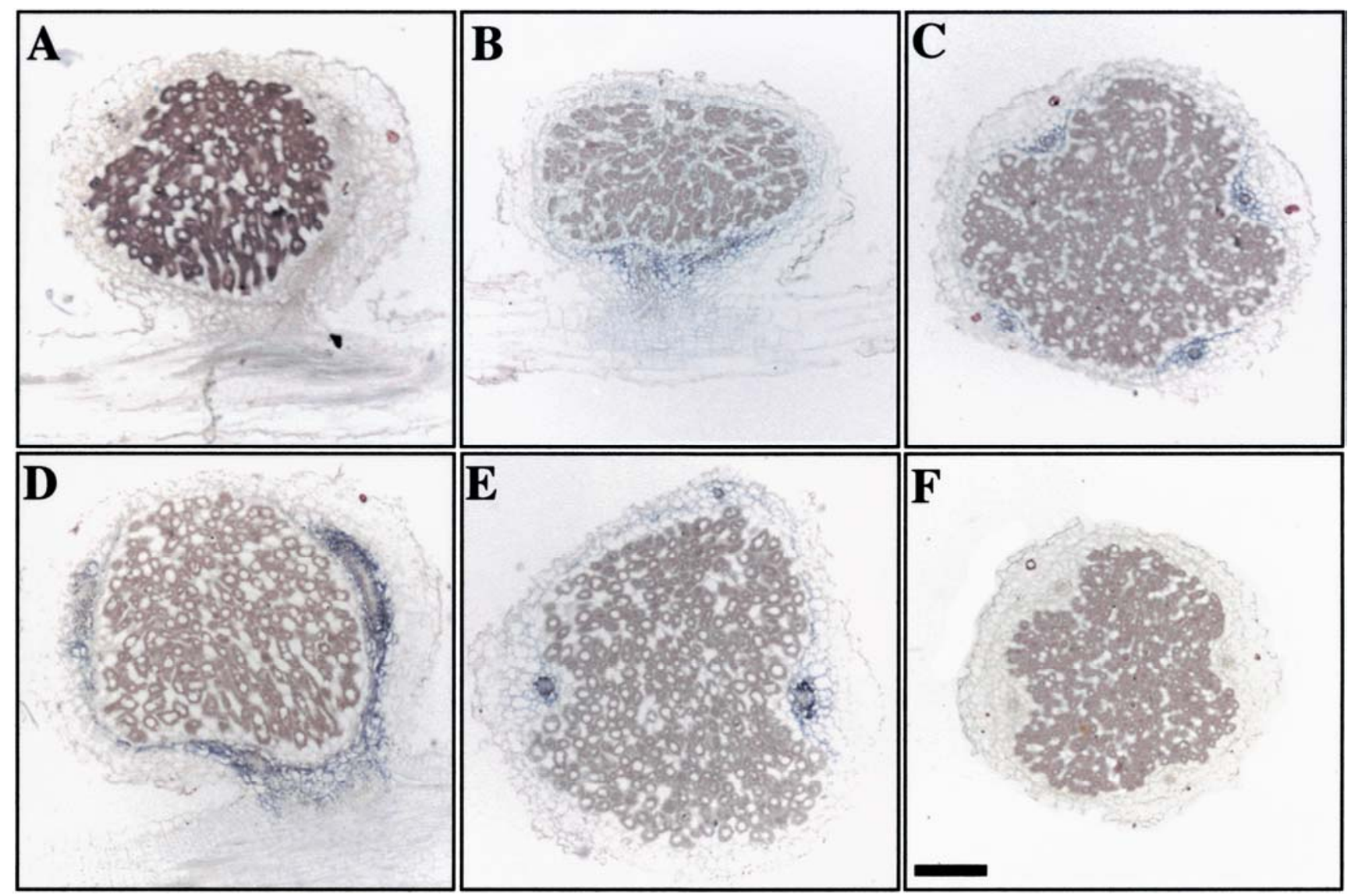

Fig. 6. In situ localization of $L j G l u R P 1$ and $L j G l u R P 2$ mRNA in effective wild-type Gifu nodules harvested from 4-week-old plants. A, Leghemoglobin (used as a reference); $\mathbf{B}$ and $\mathbf{C}, L j G l u R P 1 ; \mathbf{D}$ and $\mathbf{E}, L j G l u R P 2$; and $\mathbf{F}, L j G l u R P 2$ (sample micrograph). Longitudinal (A, B, and D) and traverse sections (C, $\mathrm{E}$, and F) $(10 \mu \mathrm{m})$ through the nodules were hybridized with digoxigenin-labeled antisense or sense probes. Hybridization signals are visible as purple or blue areas. No hybridization signals were detected by the sense probes, as illustrated by the sample micrograph for $L j G l u R P 2$. Scale bar $=200 \mu \mathrm{m}$. All micrographs were taken at the same magnification. 


\section{MATERIALS AND METHODS}

Plant materials.

Seeds of the parent L. japonicus Gifu B-129 along with the Fix mutants senl (Ljsym75), fenl (Ljsym76), and Ljsym81, which were derived from it (Imaizumi-Anraku et al. 1997; Kawaguchi et al. 2002; Suganuma et al. 2003), were surfacesterilized and inoculated with the root nodule bacterium $M$. loti MAFF 303099. The plants were grown in vermiculite, using a nitrogen-free nutrient solution in a controlled chamber with a 16-h day and 8-h night cycle at $26^{\circ} \mathrm{C}$, as described by ImaizumiAnraku and associates (1997). Ineffective nodules induced on the wild-type Gifu plants by inoculation with Rhizobium etli CE3 were removed under sterile conditions, as described by Banba and associates (2001).

\section{Macroarray analysis.}

cDNA macroarray analysis was carried out using the method described by Kouchi and associates (in press). The cDNA clones used to generate the macroarray were prepared from seedlings, nodule primordia, mature nodules, uninfected roots, and pods (Asamizu et al. 2000). Inserts of 18,432 nonredundant clones were amplified by polymerase chain reaction (PCR) spotted onto four nylon filters (Biodyne A; Pall, Ann Arbor, MI, U.S.A.) and fixed by ultraviolet cross-linking. Total RNAs were extracted from the nodules of 24-day-old Gifu and sen1 plants, using the RNeasy plant mini kit (Qiagen, Hilden, Germany). Nodules were harvested from approximately 50 Gifu and 70 sen 1 plants for each RNA preparation, respectively. Single-stranded cDNAs labeled with ${ }^{33} \mathrm{P}-\mathrm{dCTP}$ were prepared from each total RNA sample with AMV reverse transcriptase (TaKaRa, Shiga, Japan), using oligo dT primer (Amersham Biosciences, Piscataway, NJ, U.S.A.), and was used as probes. Hybridizations were carried out in $0.5 \mathrm{M}$ $\mathrm{Na}_{2} \mathrm{HPO}_{4}, 1 \mathrm{mM}$ EDTA, and 7\% (wt/vol) sodium dodecyl sulfate (SDS) at $65^{\circ} \mathrm{C}$ for $16 \mathrm{~h}$. After incubation, the filters were washed with $2 \times \mathrm{SSC}(1 \times \mathrm{SSC}$ is $0.15 \mathrm{M} \mathrm{NaCl}$ plus $0.015 \mathrm{M}$ sodium citrate), $1 \%$ (wt/vol) SDS at room temperature and twice with $0.1 \times \mathrm{SSC}, 0.1 \%$ (wt/vol) SDS at $65^{\circ} \mathrm{C}$, before being exposed to an imaging plate (Fuji Film, Kanagawa, Japan) for detection. The hybridization signals were captured using a STORM phosphorImager (Amersham Biosciences). Array analysis was performed using the same set of nylon filters for Gifu and sen 1 nodules and was duplicated using an independent set of nylon filters and probes from independent RNA preparations.

The mean pixel intensity within a defined area around each spot was collected using ArrayVision (Amersham Biosciences). Signal intensities of individual spots were normalized by adjusting the sum total of signal intensities of all the spots on the given filter to $1 \times 10^{6}$. Enhanced or repressed genes in sen 1 nodules compared with Gifu nodules were detected by the SAM program (Tusher et al. 2001).

\section{Northern and Southern blot analyses.}

Total RNAs were isolated using the RNeasy plant mini kit (Qiagen), except for samples from flowers and pods. The total RNAs from flowers and pods were extracted using $50 \mathrm{mM}$ Tris- $\mathrm{HCl}$ (pH 9.0), containing $50 \mathrm{mM} \mathrm{NaCl}, 0.5 \%$ (wt/vol) SDS, $25 \%$ (vol/vol) phenol saturated with Tris- $\mathrm{HCl}(\mathrm{pH} \mathrm{8.0)}$, and $1 \mathrm{mM}$ EDTA, 24\% (vol/vol) chloroform, and 1\% (vol/vol) isoamyl alcohol and then were precipitated with lithium chloride (Suganuma et al. 1995). Genomic DNA was isolated from the leaves of the wild-type Gifu plants, using DNeasy plant mini kit (Qiagen) and was digested to completion with BamHI and HindIII. Total RNAs were subjected to electrophoresis on a $1.25 \%$ (wt/vol) agarose gel that contained formaldehyde.
DNA fragments were separated on a $0.8 \%$ (wt/vol) agarose gel and were transferred to a Hybond-XL membrane (Amersham Biosciences), according to standard procedures (Sambrook et al. 1989). The insert was amplified from each clone, using PCR, and a DNA probe was prepared, using ${ }^{32} \mathrm{P}-\mathrm{dCTP}$ and the BcaBest labeling kit (TaKaRa). Hybridization and washing were carried out as described above, and the membranes were exposed to X-ray film (Eastman Kodak, Rochester, NY, U.S.A.).

\section{Sequence analysis.}

Plasmids were isolated from each clone, and their nucleotide sequences were determined using an automatic ABI PRISM 310 sequencer (Applied Biosystems, Foster City, CA, U.S.A.). Nucleotide and predicted amino acid sequences were analyzed using the GENETYX program (Software Development, Tokyo, Japan).

\section{In situ hybridization.}

In situ hybridization was carried out using the method described by Kouchi and Hata (1993). RNA probes were prepared from linearized plasmids with digoxigenin-11-UTR (Roche Diagnostics, Basel, Switzerland), and the hybridization signals

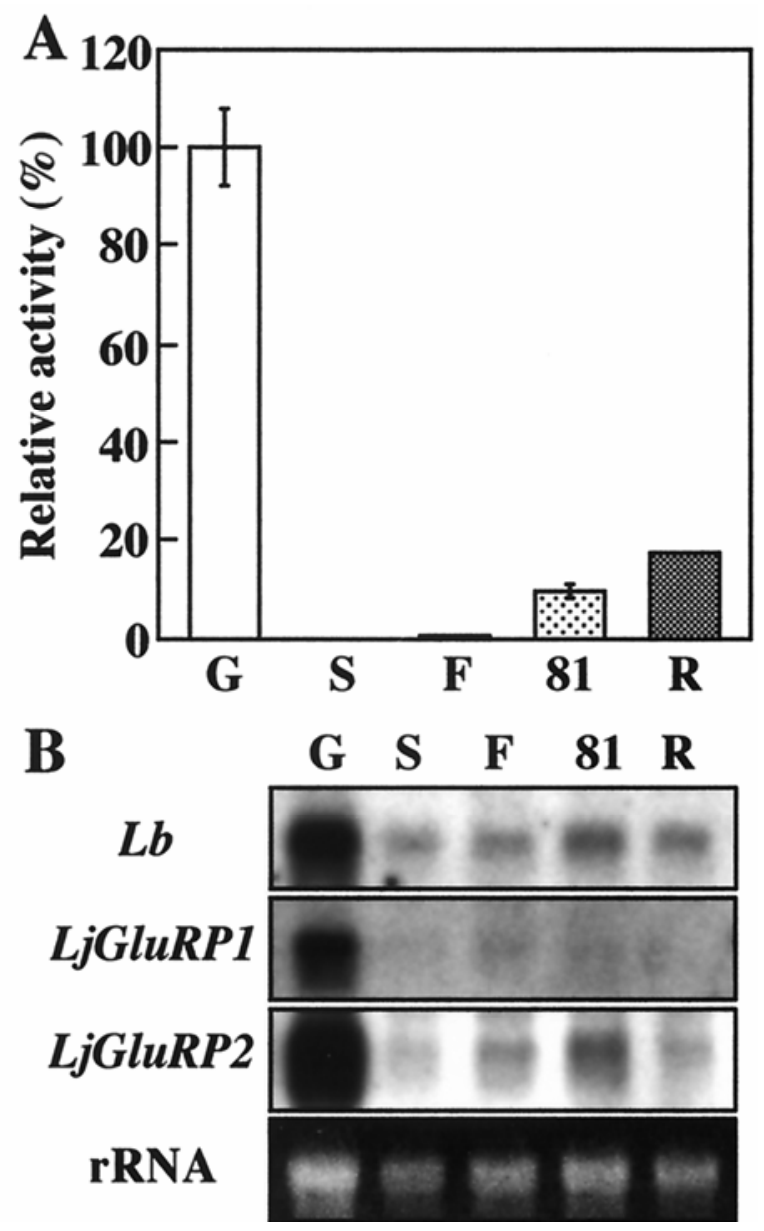

Fig. 7. A, Acetylene reduction activity and B, Northern blot analysis of LjGluRP1 and LjGluRP2 mRNA from effective Gifu nodules (G), ineffective nodules induced on sen1 (Ljsym75) (S), fen1 (Ljsym76) (F), and Ljsym81 (81) mutants, and early senescent nodules inoculated with Rhizobium etli (R). Acetylene reduction activities were expressed as relative activity compared with effective Gifu nodules. All nodules were harvested from 3-week-old plants. Leghemoglobin $(L b)$ was used as a reference in the Northern blot analysis. Each sample of total RNA $(5 \mu \mathrm{g})$ was subjected to electrophoresis on a $1.25 \%$ (wt/vol) agarose gel containing formaldehyde and then was transferred to a nylon membrane and hybridized with radiolabeled probes. rRNA was stained with ethidium bromide. 
were detected using antidigoxigenin-alkaline phosphatase conjugate with nitroblue tetrazolium salt and 5-bromo-4-chloro-3indily phosphate toluidinium salt (Roche Diagnostics).

\section{Acetylene reduction activity.}

Acetylene reduction activity of the isolated nodulated roots was measured as described previously (Suganuma et al. 2003). Nodulated roots were placed in $35-\mathrm{ml}$ vials and were incubated at $25^{\circ} \mathrm{C}$. After $30 \mathrm{~min}$, the amount of ethylene produced was determined using gas chromatography.

\section{ACKNOWLEDGMENTS}

The authors thank E. Asamizu and S. Tabata at the Kazusa DNA Research Institute, Japan, for constructing macroarray filters and providing cDNA clones. We also thank several collaborators listed by Kouchi and associates (in press) for constructing the macroarray filters. This work was supported by special coordination funds for promoting science and technology from the Japanese Ministry of Education, Culture, Sports, Science and Technology.

\section{LITERATURE CITED}

Altschul, S. F., Madden, T. L., Schaffer, A. A., Zhang, J., Zhang, Z., Miller, W., and Lipman, D. J. 1997. Gapped BLAST and PSI-BLAST: A new generation of protein database search programs. Nucleic Acids Res. 25:3389-3402.

Appleby, C. A. 1984. Leghemoglobin and Rhizobium respiration. Ann. Rev. Plant Physiol. 35:443-478.

Asamizu, E., Nakamura, Y., Sato, S., and Tabata, S. 2000. Generation of 7137 non-redundant expressed sequence tags from a legume, Lotus japonicus. DNA Res. 7:127-130.

Banba, M., Siddique, A. B. M., Kouchi, H., Izui, K., and Hata, S. 2001. Lotus japonicus forms early senescent root nodules with Rhizobium etli. Mol. Plant-Microbe Interact. 14:173-180.

Colebatch, G., Kloska, S., Trevaskis, B., Freund, S., Altmann, T., and Udvardi, M. K. 2002. Novel aspects of symbiotic nitrogen fixation uncovered by transcript profiling with cDNA arrays. Mol. Plant-Microbe Interact. 15:411-420.

Davies, C., and Robinson, S. P. 2000. Differential screening indicates a dramatic change in mRNA profiles during grape berry ripening. Cloning and characterization of cDNAs encoding putative cell wall and stress response proteins. Plant Physiol. 122:803-812.

Dickstein, R., Prusty, R., Peng, T., Ngo, W., and Smith, M. E. 1993. $E N O D 8$, a novel early nodule-specific gene, is expressed in empty alfalfa nodules. Mol. Plant-Microbe Interact. 6:715-721.

Dobert, R. C., Rood, S. B., and Blevins, D. G. 1992. Gibberellins and the legume-Rhizobium symbiosis. I. Endogenous gibberellins of lima bean (Phaseolus lunatus L.) stems and nodules. Plant Physiol. 98:221-224.

Endre, G., Kereszt, A., Kevei, Z., Mihacea, S., Kaló, P., and Kiss, G. B. 2002. A receptor kinase gene regulating symbiotic nodule development. Nature 417:962-966.

Fedorova, M., van de Mortel, J., Matsumoto, P. A., Cho, J., Town, C. D., VandenBosch, K. A., Gantt, J. S., and Vance, C. P. 2002. Genome-wide identification of nodule-specific transcripts in the model legume Medicago truncatula. Plant Physiol. 130:519-537.

Frugier, F., Poirier, S., Satiat-Jeunemaître, B., Kondorosi, A., and Crespi, M. 2000. A krüppel-like zinc finger protein is involved in nitrogen-fixing root nodule organogenesis. Genes Dev. 14:475-482.

Gamas, P., Niebel, F. C., Lescure, N., and Cullimore, J. V. 1996. Use of a subtractive hybridization approach to identify new Medicago truncatula genes induced during root nodule development. Mol. Plant-Microbe Interact. 4:233-242.

Gamas, P., de Billy, F., and Truchet, G. 1998. Symbiosis-specific expression of two Medicago truncatula nodulin genes, MtN1 and MtN13, encoding products homologous to plant defense proteins. Mol. PlantMicrobe Interact. 5:393-403.

Geurts, R., and Bisseling, T. 2002. Rhizobium Nod factor perception and signaling. Plant Cell Suppl. S239-S249.

Gordon, A. J., Minchin, F. R., James, C. L., and Komina, O. 1999. Sucrose synthase in legume nodules is essential for nitrogen fixation. Plant Physiol. 120:867-877.

Guan, C., Akkermans, A. D. L., van Kammen, A., Bisseling, T., and Pawlowski, K. 1997. ag13 is expressed in Alnus glutinosa nodules in infected cells during endosymbiont degradation and in the nodule pericycle. Physiol. Plant. 99:601-607.
Guenther, J. F., and Roberts, D. M. 2000. Water-selective and multifunctional aquaporins from Lotus japonicus nodules. Planta 210:741-748.

Häser, A., Robinson, D. L., Duc, G., and Vance, C. P. 1992. A mutation in Vicia faba results in ineffective nodules with impaired bacteroid differentiation and reduced synthesis of late nodulins. J. Exp. Bot. 43:13971407

Hernández-Jiménez, M. J., Lucas, M. M., and de Felipe, M. R. 2002. Antioxidant defence and damage in senescing lupin nodules. Plant Physiol. Biochem. 40:645-657.

Hunter, W. J. 1993. Ethylene production by root nodules and effect of ethylene on nodulation in Glycine max. Appl. Environ. Microbiol. 59:1947-1950.

Imaizumi-Anraku, H., Kawaguchi, M., Koiwa, H., Akao, S., and Syono, K. 1997. Two ineffective-nodulating mutants of Lotus japonicus: Different phenotypes caused by the blockage of endocytotic bacterial release and nodule maturation. Plant Cell Physiol. 38:871-881.

Journet, E. P., van Tuinen, D., Gouzy, J., Crespeau, H., Carreau, V., Farmer, M. J., Niebel, A., Schiex, T., Jaillon, O., Chatagnier, O., Godiard, L., Micheli, F., Kahn, D., Gianinazzi-Pearson, V., and Gamas, P. 2002. Exploring root symbiotic programs in the model legume Medicago truncatula using EST analysis. Nucleic Acids Res. 30:55795592.

Kato, T., Kawashima, K., Miwa, M., Mimura, Y., Tamaoki, M., Kouchi, H., and Suganuma, N. 2002. Expression of genes encoding late nodulins characterized by a putative signal peptide and conserved cysteine residues is reduced in ineffective pea nodules. Mol. Plant-Microbe Interact. 15:129-137.

Kawaguchi, M., Imaizumi-Anraku, H., Koiwa, H., Niwa, S., Ikuta, A., Syono, K., and Akao, S. 2002. Root, root hair, and symbiotic mutants of the model legume Lotus japonicus. Mol. Plant-Microbe Interact. 15:17-26.

Kawashima, K., Suganuma, N., Tamaoki, M., and Kouchi, H. 2001. Two types of pea leghemoglobin genes showing different $\mathrm{O}_{2}$-binding affinities and distinct patterns of spatial expression in nodules. Plant Physiol. 125:641-651

Kouchi, H., and Hata, S. 1993. Isolation and characterization of novel nodulin cDNAs representing genes expressed at early stages of soybean nodule development. Mol. Gen. Genet. 238:106-119.

Kouchi, H., Shimomura, K., Hata, S., Hirota, A., Wu, G. J., Kumagai, H., Tajima, S., Suganuma, N., Suzuki, A., Aoki, T., Hayashi, M., Yokoyama, T., Ohyama, T., Asamizu, E., Kuwata, C., Shibata, D., and Tabata, S. 2004. Large-scale analysis of gene expression profiles during early stages of root nodule formation in a model legume, Lotus japonicus. DNA Res. 11:263-274

Lanfranco, L., Bolchi, A., Ros, E. C., Ottonello, S., and Bonfante, P. 2002. Differential expression of a metallothionein gene during the presymbiotic versus the symbiotic phase of an arbuscular mycorrhizal fungus. Plant Physiol. 130:58-67.

Ledger, S. E., and Gardner, R. C. 1994. Cloning and characterization of five cDNAs for genes differentially expressed during fruit development of kiwifruit (Actinidia deliciosa var. deliciosa). Plant Mol. Biol. 25:877-886.

Limpens, E., Franken, C., Smit, P., Willemse, J., Bisseling, T., and Geurts, R. 2003. LysM domain receptor kinases regulating rhizobial Nod factor-induced infection. Science 302:630-633.

Madsen, E. B., Madsen, L. H., Radutoiu, S., Olbryt, M., Rakwalska, N., Szczyglowski, K., Sato, S., Kaneko, T., Tabata, S., Sandal, N., and Stougaard, J. 2003. A receptor kinase gene of the LysM type is involved in legume perception of rhizobial signals. Nature 425:637-640

Manen, J. F., Simon, P., Van Slooten, J. C., Osterås, M., Frutiger, S., and Hughes, G. 1991. A nodulin specifically expressed in senescent nodules of winged bean is a protease inhibitor. Plant Cell 3:259-270.

Mergaert, P., Nikovics, K., Kelemen, Z., Maunoury, N., Vaubert, D., Kondorosi, A., and Kondorosi, E. 2003. A novel family in Medicago truncatula consisting of more than 300 nodule-specific genes coding for small, secreted polypeptides with conserved cysteine motifs. Plant Physiol. 132:161-173.

Moreau, S., Thomson, R. M., Kaiser, B. N., Trevaskis, B., Guerinot, M. L., Udvardi, M. K., Puppo, A., and Day, D. A. 2002. GmZIP1 encodes a symbiosis-specific zinc transporter in soybean. J. Biol. Chem. 277:4738-4746.

Naito, Y., Fujie, M., Usami, S., Murooka, Y., and Yamada, T. 2000. The involvement of a cysteine proteinase in the nodules development in Chinese milk vetch infected with Mesorhizobium huakuii subsp. rengei. Plant Physiol. 124:1087-1095.

Park, J. H., Oh, S. A., Kim, Y. H., Woo, H. R., and Nam, H. G. 1998. Differential expression of senescence-associated mRNAs during leaf senescence induced by different senescence-inducing factors in Arabidopsis. Plant Mol. Biol. 37:445-454. 
Pathirana, S. M., Vance, C. P., Miller, S. S., and Gantt, J. S. 1992. Alfalfa root nodule phosphoenolpyruvate carboxylase: Characterization of the cDNA and expression in effective and plant-controlled ineffective nodules. Plant Mol. Biol. 20:437-450.

Pladys, D., and Vance, C. P. 1993. Proteolysis during development and senescence of effective and plant gene-controlled ineffective alfalfa nodules. Plant Physiol. 103:379-384.

Purdom, D., and Trese, A. T. 1995. Morphological and molecular characteristics of host-conditioned ineffective root nodules in cowpea. Plant Physiol. 109:239-244.

Radutoiu, S., Madsen, L. H., Madsen, E. B., Felle, H. H., Umehara, Y., Gronlund, M., Sato, S., Nakamura, Y., Tabata, S., Sandal, N., and Stougaard, J. 2003. Plant recognition of symbiotic bacteria requires two LysM receptor-like kinases. Nature 425:585-592.

Robinson, D. L., Trepp, G., Gregerson, R. G., Twary, S. N., Roeven, R., Gantt, J. S., and Vance, C. P. 1999. Cloning and developmental expression of a nodule-enhanced sucrose synthase cDNA from alfalfa. Pages 23-31 in: Highlights of Nitrogen Fixation Research. E. Martínez, and G. Hernández, eds. Kluwer Academic/Plenum Publishers, NY, U.S.A.

Sambrook, J., Fritsch, E. F., and Maniatis, T. 1989. Molecular Cloning: A Laboratory Manual, 2nd ed. Cold Spring Harbor Laboratory Press, Cold Spring Harbor, NY, U.S.A.

Schauser, L., Roussis, A., Stiller, J., and Stougaard, J. 1999. A plant regulator controlling development of symbiotic root nodules. Nature 402:191-195.

Schultze, M., and Kondorosi, A. 1998. Regulation of symbiotic root nodule development. Annu. Rev. Genet. 32:33-57.

Shi, L., Twary, S. N., Yoshioka, H., Gregerson, R. G., Miller, S. S. Samac, D. A., Gantt, J. S., Unkefer, P. J., and Vance, C. P. 1997. Nitrogen assimilation in alfalfa: Isolation and characterization of an asparagine synthetase gene showing enhanced expression in root nodules and dark-adapted leaves. Plant Cell 9:1339-1356.

Sikorski, M. M., Biesiadka, J., Kasperska, A. E., Kopcinska, J., Lotocka B., Golinowski, W., and Legocki, A. B. 1999. Expression of genes en- coding PR10 class pathogenesis-related proteins is inhibited in yellow lupine root nodules. Plant Sci. 149:125-137.

Stougaard, J. 2000. Regulators and regulation of legume root nodule development. Plant Physiol. 124:531-540.

Stracke, S., Kistner, C., Yoshida, S., Mulder, L., Sato, S., Kaneko, T., Tabata, S., Sandal, N., Stougaard, J., Szczyglowski, K., and Parniske, M. 2002. A plant receptor-like kinase required for both bacterial and fungal symbiosis. Nature 417:959-962.

Suganuma, N., Tamaoki, M., and Kouchi, H. 1995. Expression of nodulin genes in plant-determined ineffective nodules of pea. Plant Mol. Biol. 28:1027-1038.

Suganuma, N., Okada, Y., and Kanayama, Y. 1997. Isolation of a cDNA for nodule-enhanced phosphoenolpyruvate carboxylase from pea and its expression in effective and plant-determined ineffective pea nodules. J. Exp. Bot. 48:1165-1173.

Suganuma, N., Watanabe, M., Yamada, T., Izuhara, T., Yamamoto, K., Nishimura, M., and Toriyama, K. 1999. Involvement of ammonia in maintenance of cytosolic glutamine synthetase activity in Pisum sativum nodules. Plant Cell. Physiol. 40:1053-1060.

Suganuma, N., Nakamura, Y., Yamamoto, M., Ohta, T., Koiwa, H., Akao, S., and Kawaguchi, M. 2003. The Lotus japonicus Senl gene controls rhizobial differentiation into nitrogen-fixing bacteroids in nodules. Mol. Genet. Genomics 269:312-320.

Szczyglowski, K., Hamburger, D., Kapranov, P., and de Bruijn, F. J. 1997. Construction of a Lotus japonicus late nodulin expressed sequence tag library and identification of novel nodule-specific genes. Plant Physiol. 114:1335-1346.

Tusher, V. G., Tibshirani, R., and Chu, G. 2001. Significance analysis of microarrays applied to the ionizing radiation response. Proc. Natl. Acad. Sci. U.S.A. 98:5116-5121.

Vance, C. P., Gregerson, R. G., Robinson, D. L., Miller, S. S., and Gantt, J. S. 1994. Primary assimilation of nitrogen in alfalfa nodules: Molecular features of the enzymes involved. Plant Sci. 101:51-64.

Whitehead, L. F., and Day, D. A. 1997. The peribacteroid membrane. Physiol. Plant 100:30-44. 